\title{
The Torquay Conference
}

\section{The benefit is in the} experience and the way that experience changes you and the way you think

Mike Grace e-mail:mgrace.bdj@dial.pipex.com

\begin{abstract}
D unning a conference, exhibition or simply a course can sometimes feel like a pretty thankless task. You have all the responsibility of contacting the people, advertising and promoting the event, arranging the speakers and (perhaps worst of all) designing the programme. Then, if everything goes well, the speakers get the praise, and if things go wrong you get all the blame.
\end{abstract}

The reason that I started this leader with a somewhat downbeat introduction is because I suspect that the organisers of the BDA Conference can relate to it rather well. However, due to the undoubted success of this year's meeting in Torquay I would like to put on record how much I personally enjoyed the whole conference to add to the $B D J$ 's own report inside this issue. I was not the only one who enjoyed the meeting, as most of the exhibitors will know. You can always tell a good conference because the exhibition is quiet during the workshops, lectures and other sessions, but manic during the break.

In my view, BDA Conferences have been steadily improving over the last few years, and it is time the perception of an outdated number of speakers talking to empty rooms while near-retired BDA members share drinks on the terrace is put to rest. Unlike dentists in other countries who flock to national conferences, UK dentists still seem to suffer from a distinct lack of enthusiasm for their own event. This is a shame, as there is no substitute for the real thing, and I suspect that, for many, the BDA Conference is still regarded as an outdated and outmoded excuse for people to get together, rather than an event that can benefit themselves and (more importantly) their success and enjoyment in dentistry.

So what are the benefits of attendance at such an event? Why should someone leave the comfort of their home and family, lose income for a day or two, travel a considerable distance and pay to stay in a hotel for a few days, just to go to a few lectures, visit some tradestands and perhaps meet a few old friends?

Put like that, I suppose it does begin to sound unattractive. But if we lived our lives with that kind of mindset then we would never go out (why spend money on shoe leather?) visit a restaurant (you can always microwave an instant meal) or go to the theatre or cinema (it will eventually be shown on the television). The difference is in the experience itself, and more importantly, the way that experience affects us. As human beings we need to experience to develop, and our experiences enrich and shape our lives.

Attending the conference is the same. The size of the event means the experience is much more than simply attending a course. It is richer. There is much more to learn from. The time spent after the sessions also provides the opportunity to meet with others, to enjoy the social events with new people, to learn and develop. Besides this, many of the traditional excuses for not attending have gone, such as what to do with the children now a crèche is available. The whole family can come as well, and this year the weather in Torquay — unbroken sunny skies the whole time - was a real bonus for those who chose to do so. But, as I said earlier, the real benefit is in the experience itself and the way that experience changes you and the way you think.

Next year Dentistry 2000 will be an event for the whole of dentistry, involving as many groups and societies as possible. No one group, association or event is predominating, allowing the participants (in other words all of us) to truly share in a major experience with everyone else involved in dentistry. It sounds exciting. I believe those who attend will benefit in many different ways, and I guarantee it will be an experience that will lead us into the new millennium. 